\title{
Contents of Volume 2
}

Bailar, B.A., Nonresponse: What it is and what we do about it 381

Barta, J., see A. Klas 417

Battista, G. and C. Cataldi, Production and utilization of high temperature geothermal energy - Statistical data processing methodology 63

Bethlehem, J.G., see H.M.P. Kersten $\quad 369$

Brophy, H.F., How friendly is 'user-friendly'? 407

Callies, J.M., The management of identification registers by statistical offices

Camus, B., T. Ferre, M. Rousset and M.-H. Tamisier, The French Unified System of Bussiness Statistics

Cataldi, C., see G. Battista

Central Institute of Statistics of Italy Analysis and planning proposals of the -

Conference of European Statisticians

Forthcoming meetings convened by the -

$115,221,327,427$

List of documents issued (July 1982-June 1983)

Recent work

Drechsler, L., Recent developments in the national accounting system of Hungary

Dubois, M., Statistical office and studies

Duckworth, D., R. Knight, M.D. Warren, Using the ICIDH in household surveys: problems and possibilities

Ferre, T., see B. Camus

Gerisch, G., On the conceptual development of energy statistics in terms of useful energy

Heldal, J. and T. Østdahl, Synoptic monitoring of water quality and water resources. A suggestion on population and sampling approaches.

Kersten, H.M.P. and J.G. Bethlehem, Exploring and reducing the nonresponse bias by asking the basic question

Klas, A. and J. Barta, The use of mini- and microcomputers as integrated parts of statistical data processing systems

Knight, R., see D. Duckworth

Kristiansson, K-E., Gross-flow estimates in the Swedish labour forle surveys

Laganier, J., The possible impact of national accounts and balances on the development of frameworks for environment statistics

Lutz, H., Experiences in data structuring gained from running a general statistical data bank system 
Molnar, A., Statistics on the production and use of low temperature geothermal energy - Methodological problems

Noordhoek, J.A. and O.K. Petersen, Household and family concepts in danish population registers and surveys 169

Nourney, M., Seasonal adjustment by frequency determined filter procedures

Østdahl, T., see J. Heldal 393

Petersen, O.K., see J.A. Noordhoek 169

Quelennec, H., The business statistics system in France and consistency between sources 137

Rapaport, E., Legal and technical means for protecting data in the production of statistics

Rousset, M., see B. Camus 149

Saebø, H.V., Modelling energy demand: considerations of price impacts and statistics

Sande, G., Automated cell suppression to preserve confidentiality of business statistics

Siddique, A., Commodity price indices - A historical and methodological review

Šoltés, D., The metainformation system and the conceptual level of statistical data modelling

The Statistical Computing Project

The System of National Accounts: Review of major issues and proposals for future work

Part I

Part II

Part III

Szilágyi, G., International comparisons - Types and methods 345

Tamisier, M.-H., see B. Camus 149

Warren, M.D., see D. Duckworth $\quad 85$

Williams, N.J.R., Relational modelling for Adabas implementations at the Australian Bureau of Statistics 